Research Article Genetics of Microorganisms

\title{
An efficient Agrobacterium tumefaciens-mediated transformation method for Simplicillium subtropicum (Hypocreales: Cordycipitaceae)
}

\author{
Nicolau Sbaraini ${ }^{1,2}$ (1), Mariana Vieira Tomazett ${ }^{3}$, Augusto Bartz Penteriche ${ }^{1}$, Relber Aguiar Gonçales ${ }^{4,5}$, \\ Matheus da Silva Camargo ${ }^{1}$, Alexandre Melo Bailão ${ }^{3}$ (D), Clayton Luiz Borges ${ }^{3}$ (D), Augusto Schrank ${ }^{1,2}$, \\ Célia Maria de Almeida Soares ${ }^{3}$ and Charley Christian Staats ${ }^{1,2}$ (1) \\ ${ }^{I}$ Universidade Federal do Rio Grande do Sul, Centro de Biotecnologia, Programa de Pós-graduação \\ em Biologia Celular e Molecular, Porto Alegre, RS, Brazil. \\ ${ }^{2}$ Rede Avançada em Biologia Computacional (RABICÓ), Petrópolis, RJ, Brazil. \\ ${ }^{3}$ Universidade Federal de Goiás, Instituto de Ciências Biológicas, Laboratório de Biologia Molecular, \\ Goiânia, GO, Brazil. \\ ${ }^{4}$ University of Minho, School of Medicine, Life and Health Sciences Research Institute (ICVS), Braga, \\ Portugal. \\ ${ }^{5}$ ICVS/3B's - PT Government Associate Laboratory, Braga/Guimarães, Portugal.
}

\begin{abstract}
Filamentous fungi are the organisms of choice for most industrial biotechnology. Some species can produce a variety of secondary metabolites and enzymes of commercial interest, and the production of valuable molecules has been enhanced through different molecular tools. Methods for genetic manipulation and transformation have been essential for the optimization of these organisms. The genus Simplicillium has attracted increased attention given several potential biotechnological applications. The Simplicillium genus harbors several entomopathogenic species and some isolates have been explored for bioremediation of heavy metal contaminants. Furthermore, the myriad of secondary metabolites isolated from Simplicillium spp. render these organisms as ideal targets for deep exploration and further biotechnological mining possibilities. However, the lack of molecular tools hampered the exploration of this genus. Thus, an Agrobacterium tumefaciens-mediated transformation method was established for Simplicillium subtropicum, employing the far-red fluorescent protein TURBOFP635/Katushka, as a visual marker, and the selection marker SUR gene, that confers resistance to chlorimuron ethyl. Notably, one round of transformation using the established method yielded almost 400 chlorimuron resistant isolates. Furthermore, these transformants displayed mitotic stability for, at least, five generations. We anticipate that this method can be useful for deep molecular exploration and improvement of strains in the Simplicillium genus.
\end{abstract}

Keywords: Simplicillium, Simplicillium subtropicum, Agrobacterium tumefaciens, Katushka, Agrobacterium tumefaciens-mediated transformation.

Received: March 13, 2021; Accepted: June 15, 2021.

\section{Introduction}

The family Cordycipitaceae harbors filamentous fungi of commercial and scientific interest. The most recognizable member of this family, the Beauveria genus, embraces entomopathogenic species (Zimmermann, 2007). Several commercial formulations of Beauveria bassiana are available worldwide for agricultural pests biological control (Faria and Wraight, 2007). Similarly, species from the Cordyceps genus are retailed, given several potential health benefits (Tuli et al., 2014). Furthermore, some species from this family can be mycoparasitic (Kepler et al., 2017). For instance, the dry bubble disease caused by Lecanicillium fungicola is a persistent problem in the cultivation of Agaricus bisporus (Berendsen et al., 2010), while Akanthomyces psalliotae is

Send correspondence to Charley Christian Staats. Universidade Federal do Rio Grande do Sul, Centro de Biotecnologia, Programa de Pós-graduação em Biologia Celular e Molecular, Av. Bento Gonçalves, 9500 - Setor 4, Prédio 43421, Lab. 219, Porto Alegre, RS, Brazil. E-mail: staats @ufrgs.br. an entomopathogenic, mycoparasitic, and nematophagous fungus (Harm et al., 2018).

The earliest diverging lineage in the family Cordycipitaceae is the Simplicillium genus (Kepler et al., 2017). This genus has attracted interest for several potential applications, ranging from biological control to remediation by toxic metal accumulation. Some mycoparasitic Simplicillium species can be employed for biological control of oomycetes and fungi, as Simplicillium lamellicola and Simplicillium lanosoniveum, while the latter species can also be a plant pathogen (Chen et al., 2008; Ward et al., 2012; Shin et al., 2017). Simplicillium chinense has been explored for biosorption of cadmium and lead (Jin et al., 2019; Jin et al., 2020). Additionally, this species can ameliorate the phytoremediation performance of the water-reed Phragmites communis (Jin et al., 2019).

Several secondary metabolites have been isolated from Simplicillium spp. Simplicilliumtides, from Simplicillium obclavatum, possess a broad range of biological activities, including antibacterial, antifungal, antiviral, antifouling, cytotoxic, as well as acetylcholinesterase inhibitory activity 
(Youssef et al., 2019). Aogacillins A and B, produced by Simplicillium sp. FKI-5985, circumvent arbekacin resistance in methicillin-resistant Staphylococcus aureus (Takata et al., 2013). Verlamelins A and B and sinulariapeptide A, isolated from a soft coral-associated Simplicillium sp., showed antifungal activity against Pyricularia oryzae and Colletotrichum asianum, respectively (Dai et al., 2018). Simpotentin, isolated from the culture broth of Simplicillium minatense, has been described as a potentiator of amphotericin B activity against Candida albicans and Cryptococcus neoformans (Uchida et al., 2019). Furthermore, several compounds isolated from Simplicillium lanosoniveum have shown antibacterial, antifungal and phosphodiesterase 5 inhibitory activity (Rukachaisirikul et al., 2019).

Contrasting with the biotechnological potential of the Simplicillium genus, there is no method for genetic modification of these species. Thus, to address this obstacle, a highly efficient Agrobacterium tumefaciens-mediated transformation (ATMT) method was standardized for Simplicillium subtropicum, employing, as an in vivo tag, the reporter far-red fluorescent protein TURBOFP635/ Katushka (Kat) (Shcherbo et al., 2007), and, as a selection marker, the $S U R$ gene.

\section{Material and Methods}

\section{Strains and culture media}

S. subtropicum strain IBCB 79 was originally isolated from a dead Leptopharsa heveae collected in Mato Grosso, Brazil. This strain is deposited in the fungal collection "Coleção de Culturas de Entomopatógenos Oldemar Cardim Abreu" located in São Paulo, Brazil. Before subsequent experiments, this strain was grown at $28{ }^{\circ} \mathrm{C}$ in solid Cove's Complete Medium (MCc), as previously described (Sbaraini et al., 2019). Maintenance of transformants were in solid Cove's Medium (MC), as described by Sbaraini and coworkers (2019), and 10 $\mu \mathrm{g} / \mathrm{mL}$ of Chlorimuron Ethyl (CE) was employed. Escherichia coli TG2 was employed in routine cloning, and Agrobacterium tumefaciens strains EHA105 and LBA1100 were employed to perform the ATMT of S. subtropicum strain IBCB 79. Bacteria were obtained from the laboratory's collection and maintained in Luria-Bertani (LB) medium with the appropriate antibiotics (Green and Sambrook, 2012).

\section{Species identification and phylogeny}

To ensure that strain IBCB 79 is a member of the Simplicillium genus, the internal transcribed spacer (ITS) region was sequenced and analyzed. DNA was extracted employing the standard phenol/chloroform method (Green and Sambrook, 2012). PCR reaction was performed following the standard protocols. DNA sequencing was performed by ACTGene Análises Moleculares (Brazil, RS) employing Sanger sequencing (Applied Biosystems, AB3500). The sequence (MT822178) was amended together with other sequences employed in the proposed Simplicillium genus tree described previously (Crous et al., 2018). The DNA barcode sequences were subjected to alignment reliability analyses using GUIDANCE 2.0 (alignment is shown in Supplementary Data S1), using the PRANK algorithm for sequence alignment with 100 bootstrap replicates and variable gap penalties (Loytynoja and Goldman, 2010; Sela et al., 2015). Additionally, a GUIDANCE 2.0 score cutoff of 0.93 for site removal was employed (Sela et al., 2015). The phylogenetic reconstruction was conducted with PhyML 3.1 (Maximum Likelihood) with aLRT SH-like (approximate likelihood ratio test Shimodaira-Hasegawa) branch support estimation (Guindon et al., 2010), employing GTR $+\mathrm{I}+\mathrm{G}$ as the evolutionary model.

\section{Katushka reporter plasmid construction}

For expression of the KAT gene, first, the Magnaporthe grisea acetolactate synthase enconding gene (SUR), which confers resistance to CE (Lin et al., 2011), was PCR-amplified with primers pPZP_EcoRV_SUR_F and pPZP_EcoRV_SUR_R (Table S1) and introduced in the EcoRV site of the binary vector pPZP201BK (Walton et al., 2005), to generate the plasmid pPZP201BK::SUR. The isolation of the SUR gene (sulfonylurea resistance allele $M$. grisea $I L V 1$ ) has been described previously (Sweigard et al., 1997). The SUR gene, along with its native promoter and terminator, was obtained from plasmid pCB1532 (kindly provided by Aline S. RomãoDumaresq and Nicholas Talbot). The Kat coding sequence was PCR amplified with primers gpdA_CDSKat_F and TtrpC CDSKat_Rfrom the plasmid pJAF15::H3P::Kat::H3T (i. e., the gene is under control of the Histone 3 promoter and terminator of Cryptococcus neoformans; the plasmid was kindly provided by Marilene Henning Vainstein) and cloned in the NcoI and BamHI sites of the plasmid pAN::gpdA::BAR::TrpC, to generate the plasmid pAN::gpdA::Kat::TrpC (i. e., NcoI and BamHI digestion released the BAR gene) (Haleva et al., 2020). The Kat gene expression cassette, gpdA::Kat::TrpC was PCR amplified with primers pPZP_HindIII_gpdA_Kat_F and pPZP_HindIII trpC_Kat_R, and cloned in the Eco $\bar{R}$ V site of the plasmid pPZP201BK::SUR to generate the plasmid pPZP201BK::SUR::gpdA::Kat::TrpC (primers, plasmid map, and plasmid sequence were included as Table S1, Figure S1, and Supplementary Data S2, respectively). All cloning steps were performed employing the Hot fusion protocol (Fu et al., 2015).

\section{Agrobacterium tumefaciens-mediated transformation}

The protocol used for the transformation of S. subtropicum was similar to the ATMT method used for Aspergillus awamori (Michielse et al., 2008), and Paracoccidioides brasiliensis (Almeida et al., 2007; Menino et al., 2012). Furthermore, these employed protocols were based on the work of Bundock et al. (1995), and de Groot et al. (1998). In brief, cultures of A. tumefaciens EHA105 or LBA1100 (carrying the Katushka plasmid), which were overnight grown in LB broth supplemented with antibiotics, were inoculated in 10 $\mathrm{mL}$ of freshly prepared induction medium (IM) supplemented with $400 \mu \mathrm{M}$ acetosyringone (AS) and antibiotics. The cells were grown in $\mathrm{IM}$ at $28^{\circ} \mathrm{C}$ and $180 \mathrm{rpm}$ until reaching $\mathrm{OD}_{600}$ $\mathrm{nm}$ of 0.8-0.9. Concomitantly, five days old MCc plates presenting $S$. subtropicum growth were used to prepare a fresh spore suspension. The plates were washed with Tween $800.01 \%$ (w/v) solution, the spores recovered and washed two times with liquid IM without antibiotics or AS. Spore counting was performed employing a hemocytometer and spore concentration was adjusted to the desired concentration 
$\left(1 \times 10^{6}, 1 \times 10^{7}\right.$, or $1 \times 10^{8}$ spores $\left./ \mathrm{mL}\right)$ with liquid IM without antibiotics or AS. Subsequently, one hundred $\mu \mathrm{L}$ of the A. tumefaciens resulting growth was mixed with $50 \mu \mathrm{L}$ of the $S$. subtropicum spore suspension. The A.tumefaciens-S. subtropicum mixture was kindly homogenized and pipetted over $0.45 \mu \mathrm{m}$ Hybond $\mathrm{N}+$ filter membranes disposed over solid IM supplemented with $400 \mu \mathrm{M}$ AS and antibiotics. The mixture was left evaporating for $30 \mathrm{~min}$ in the dark before co-cultivation at $24^{\circ} \mathrm{C}$ for 24,48 , and $72 \mathrm{~h}$. After cocultivation, the resulting growth (over the filter membranes), was scrapped in liquid MC supplemented with $200 \mu \mathrm{g} / \mathrm{mL}$ of cefotaxime and $10 \mu \mathrm{g} / \mathrm{mL}$ of CE and spread over MC plates supplemented with $200 \mu \mathrm{g} / \mathrm{mL}$ of cefotaxime and $10 \mu \mathrm{g} / \mathrm{mL}$ of $\mathrm{CE}$. The plates were incubated at $28^{\circ} \mathrm{C}$ until the transformants emergence. Potential transformants usually start to appear after 2 days. All transformations were performed in triplicates in two independent experiments. Emerging transformants were transferred to a new MC plate supplemented with $10 \mu \mathrm{g} / \mathrm{mLCE}$ for additional selection. Subsequently, selected transformants were cultured in MCc medium without the selection agent for five generations to evaluate mitotic stability.

\section{Screening of the transformants by fluorescent imaging}

The first screening for Kat expression was carried out by qualitative detection of the far-red fluorescence using the Living Image 3.1 software in IVIS Lumina II (PerkinElmer). The parameters were set to 60 second exposure time, excitation at $535 \mathrm{~nm}$ and $465 \mathrm{~nm}$ (for background removal), using the dsRed emission filter. Not only transformant fungal colonies were inspected, as we also checked $A$. tumefaciens EHA105 harboring the plasmid pPZP201BK::SUR::gpdA::Kat::TrpC (i.e., the observed fluorescence could come from a bacterial contaminant rather than the selected mutants). Furthermore, intracellular expression of Kat was evaluated using the FLoid Cell Imaging Station (Thermo Fisher Scientific) with the red filter parameters (excitation: $586 \mathrm{~nm}$; emission: 646 $\mathrm{nm})$. Moreover, for detailed microscopic visualization of the Kat-fluorescence, the FLoid Cell Imaging Station was also employed. In this assay, wild-type and mutant strains were microcultured in $\mathrm{MCc}\left(28^{\circ} \mathrm{C}, 4\right.$ days $)$ and posteriorly inspected.

Genomic DNA of potential transformants was extracted employing the phenol: chloroform method (Green and Sambrook, 2012). PCR to amplify SUR and KAT were also performed to evaluate the mutants (Primer sequences are described in Table S1). Subsequently, three selected mutants and the wild-type strain were evaluated by Southern blotting (Alkphos Direct Labeling and Detection System, GE Healthcare), to confirm the insertion of the Kat expression cassette and potentially evaluate the number of insertions in the genome. Genomic DNA was digested with StuI and further hybridized with a $K A T$ CDS probe.

\section{Statistics}

Statistical analyses were conducted with GraphPad Prism 6(GraphPad software). Transformation efficiencies were plotted in number of isolated transformants. Effective transformation regimes were determined by one-way ANOVA with posthoc Tukey's test $(p<0.01)$. The letters above bars indicate the statistical difference between transformation regimes.

\section{Results}

\section{S. subtropicum phylogeny}

To characterize the genetic identity of strain IBCB 79, ITS sequencing and phylogeny were employed. This step was performed due to the inherent difficulty to distinguish Simplicillium isolates from Sporothrix insectorum isolates. The ITS sequence was compared with other Simplicillium sequences used to describe Simplicillium filiforme, a new endophytic species, recently described (Crous et al., 2018). The inferred phylogenetic tree supports the inclusion of the strain IBCB 79 as $S$. subtropicum (Figure 1). Originally isolated from soil in Japan (Nonaka et al., 2013), S. subtropicum has been explored for bioremediation of copper polluted areas, displaying the best results among few selected species (Ong et al., 2017).

\section{Agrobacterium tumefaciens-mediated transformation of S. subtropicum}

For several filamentous fungi (e.g., A. awamori and Paracoccidioides spp.) the strain LBA1100 of A. tumefaciens is the most used for ATMT (Michielse et al., 2008; Fernandes et al., 2017), while, for species from Hypocreales order, the strains EHA105 or AGL1 are usually employed (Staats et al., 2007; Padilla-Guerrero and Bidochka, 2017). Thus, the $A$. tumefaciens strains EHA105 and LBA1100 were evaluated for S. subtropicum transformation. Furthermore, the effect of different spore concentrations, during co-cultivation, was also assessed. Finally, different co-cultivation periods $(24,48$, and $72 \mathrm{~h}$ ) were also evaluated. The best results were obtained employing A. tumefaciens strain EHA105 and $1 \times 10^{8}$ spores/ $\mathrm{mL}$ of $S$. subtropicum during $48 \mathrm{~h}$ of co-cultivation (Figure 2). Almost 400 transformants were obtained employing $1 \mathrm{x}$ $10^{8}$ spores $/ \mathrm{mL}$, although, it is important to notice, that $1 \times 10^{7}$ spores $/ \mathrm{mL}$ can be more suitable for routine experiments since fewer spores are needed and transformants are easily isolated. A similar number of transformants were obtained employing $1 \times 10^{7}$ spores/mL of S. subtropicum with 48 and $72 \mathrm{~h}$ of cocultivation (Figure 2) Furthermore, the results discourage the use of A. tumefaciens strain LBA1100 for the transformation of $S$. subtropicum. Notably, transformants were not obtained when A. tumefaciens strain LBA1100 was co-cultured with S. subtropicum for $72 \mathrm{~h}$ (Figure 2).

\section{Kat-fluorescence detection and mitotic stability analysis}

Transformants from the ATMT experiments, selected based on CE resistance, were first evaluated for far-red Katfluorescence using the Living Image 3.1 software implemented in the IVIS Lumina II equipment followed by intracellular analysis of Kat expression with the FLoid Cell Imaging Station. As expected, given the potential scattered insertion of the Kat expression cassette in the genome of the recipients, different mutants displayed different levels of fluorescence. Of 69 mutants evaluated for far-red Kat-fluorescence, 58 exhibited high levels of positive fluorescence (Figure 3).

To rule out that the observed fluorescence could be due to the presence of residual $A$. tumefaciens cells, we also evaluated the generated mutants by fluorescence microscopy analysis. As expected, due to the use of a strong and constitutive promoter, 


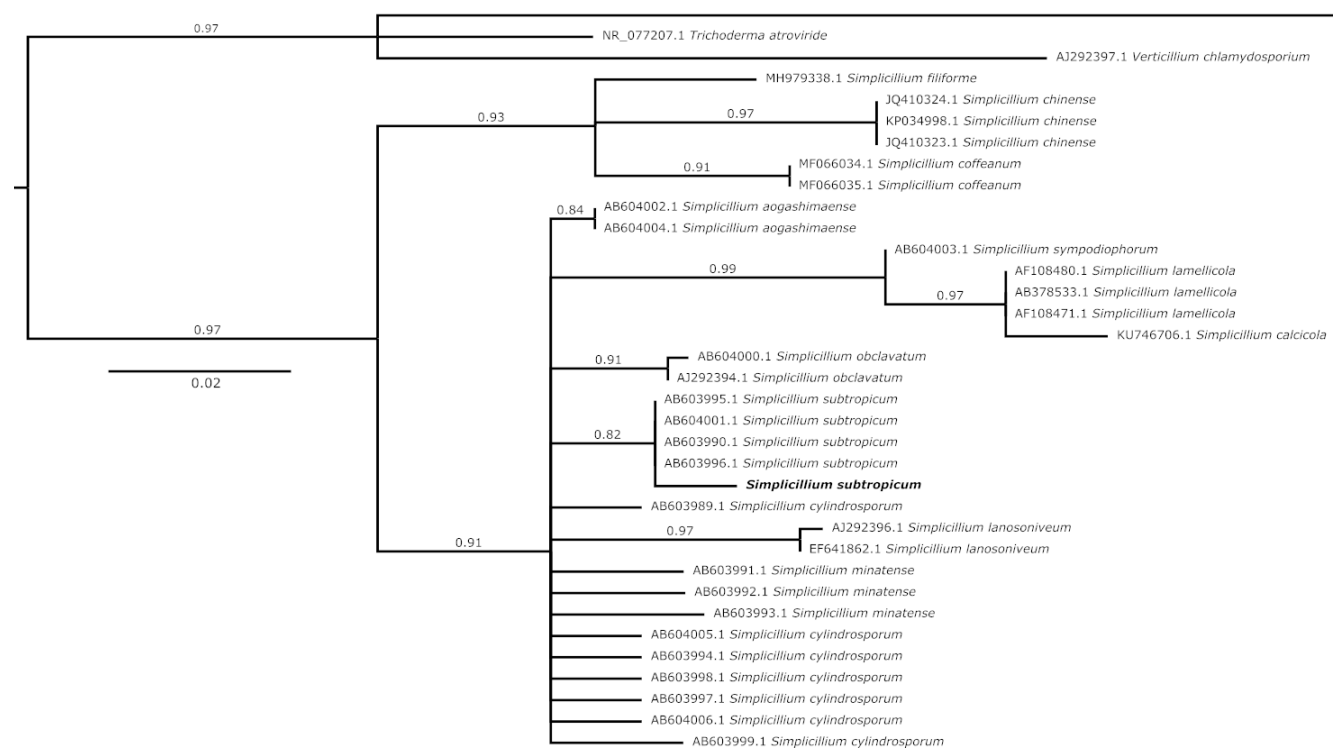

Figure 1 - Simplicillium subtropicum species phylogenetic tree. A species tree based on ITS sequences was constructed to establish the relationships between the Simplicillium species with available ITS sequences and strain IBCB 79. Bionectria vesiculosa, Trichoderma atroviride, and Verticillium chlamydosporium entries were employed as outgroup and the tree was rooted in these species. Phylogenetic analysis was performed using Maximum-likelihood. Branch support values (aLRT SH-like supports) are associated with nodes. Polytomies were included when branch support values were lower than 0.80 .

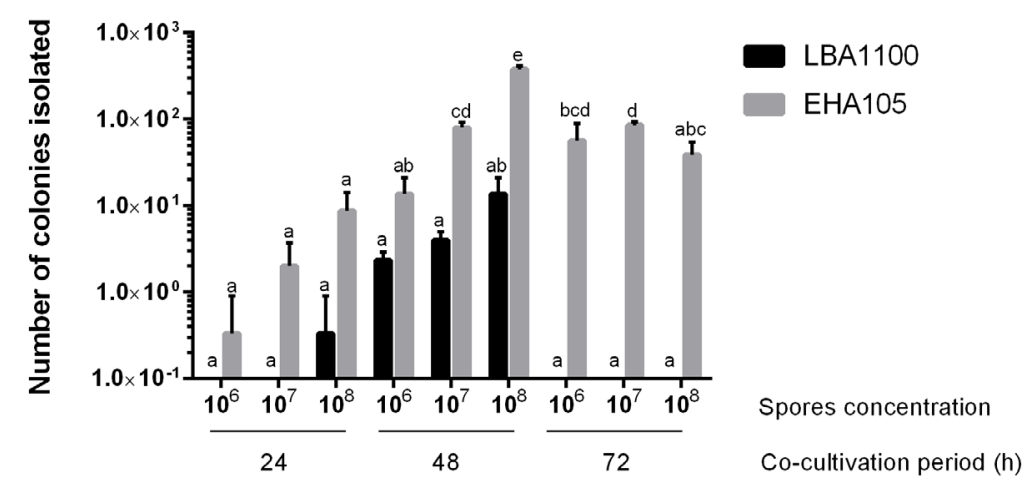

Figure 2 - Transformation efficiency. To determine the most suitable transformation protocol for $S$. subtropicum, different strains of $A$. tumefaciens were evaluated (EHA105 and LBA1100), as well as different spore concentrations $\left(1 \times 10^{6}, 1 \times 10^{7}\right.$, or $1 \times 10^{8}$ spores $\left./ \mathrm{mL}\right)$ and co-cultivation times $(24$, 48 , and $72 \mathrm{~h}$ ). The different letters above bars indicate statistical differences between transformation regimes according to one-way ANOVA analysis followed by posthoc Tukey's test $(p<0.01)$.

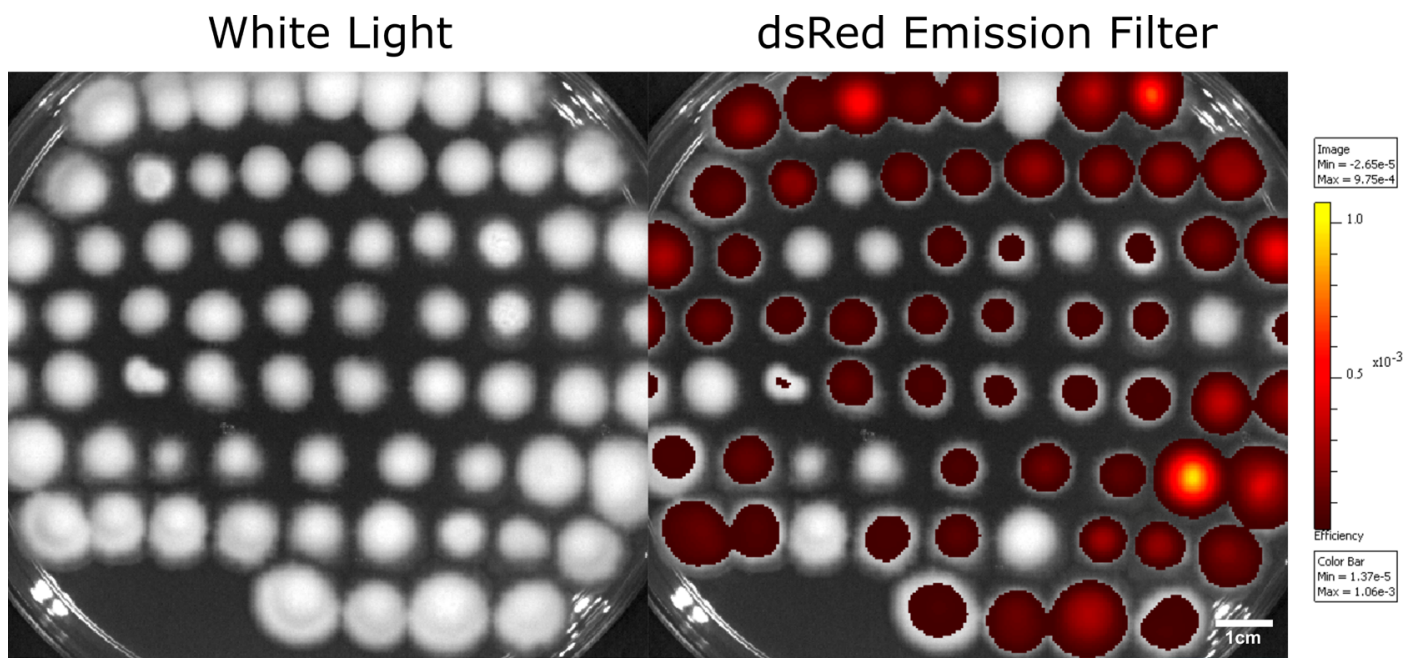

Figure 3 - Macroscopic evaluation of far-red Kat-fluorescence. Fifty-eight of sixty-nine mutants evaluated displayed the far-red Kat-fluorescence (84\%). The parameters on Living Image 3.1 (implemented in the IVIS Lumina II equipment) were set to 60 second exposure time, excitation at $535 \mathrm{~nm}$ and $465 \mathrm{~nm}$ (for background removal), using the dsRed emission filter. Left Panel, White Light. Right Panel, dsRed emission filter. 
the Kat fluorescence was detected in both mycelia and spores of a representative transformant (Figure 4). Noteworthy, while we could detect fluorescence in fungal cells, the bacterial strain harboring the plasmid pPZP201BK::SUR::gpdA::Kat::TrpC has no clear phenotype (Figure S2). Therefore, besides showing CE resistance, several transformants also carry the active Kat expression cassette, reiterating the success of the developed ATMT method.

Six mutants, which displayed the brightest far-red Katfluorescence, were chosen to assess mitotic stability. These mutants were cultivated in MCc medium without selection of CE during five generations. All mutants maintained the fluorescence even in MCc (data not shown). Moreover, the DNA of these mutants was extracted, and PCR was employed to evaluate the presence of the SUR gene and the Kat expression cassette (Figure 5A). All mutants presented amplification for the SUR gene $(\sim 2800 \mathrm{bp}$; Figure $5 \mathrm{~B})$. Additionally, three selected mutants were also PCR-assayed for the KAT CDS (Figure 5C), and the same mutants were inspected by Southern blotting (Figure 5D). Therefore, even with the brightest far-red Kat-fluorescence (i. e., pointing for putative stronger expression/ higher protein content) the insertions in the $S$. subtropicum genome were stable for at least five generations. Notably, the mutants that displayed the brightest far-red Kat-fluorescence presented at least two insertions of the Kat expression cassette in the genome (Figure 5D). The stability of the construct, together with the usefulness of the macro- and micro-visualization of the Kat fluorescence (Figures 3 and 4, respectively) can be valuable for genetic studies in Simplicillium.

\section{Discussion}

Methods for the transformation of fungi are basic to understand molecular aspects of these species. In addition, the impact of genetic manipulation has revolutionized modern biotechnology, and filamentous fungi are a well-established and important source of enzymes and bioactive molecules (Idnurm and Meyer, 2014; Khan et al., 2016). The implementation of $A$. tumefaciens as a tool remodeled several approaches to discover and understand gene function in many fungal species (Idnurm et al., 2017). The Simplicillium genus has drawn increase scientific interest and a method for genetic transformation was still absent.

Different strategies have been used for the transformation of filamentous fungi (Ruiz-Díez, 2002; Li et al., 2017). These methods range from shock-wave-mediated transformation to protoplast-mediated transformation and ATMT (Li et al., 2017).
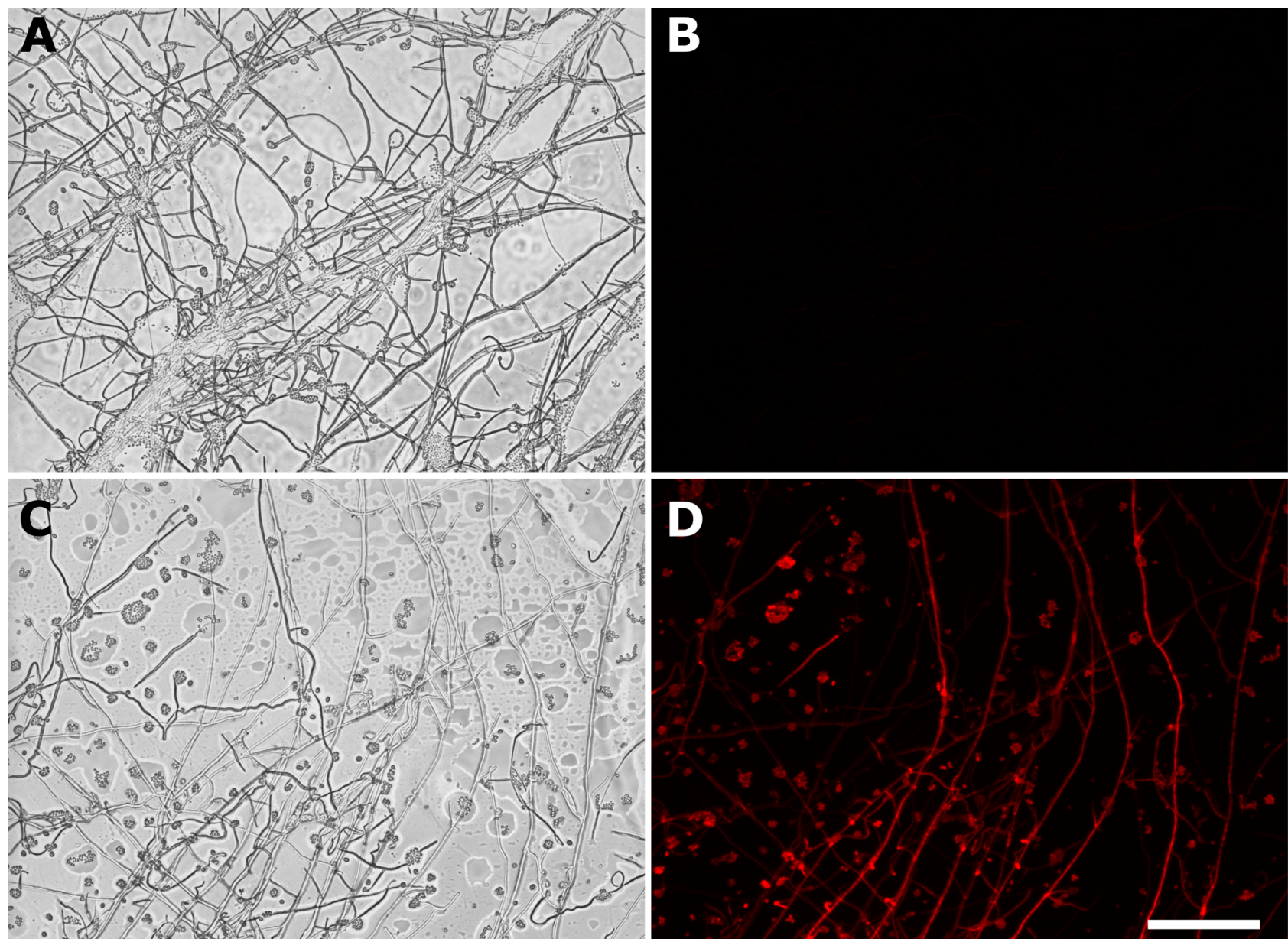

Figure 4 - Microscopic evaluation of far-red Kat-fluorescence. Isolated mutants were evaluated for Kat-fluorescence employing the FLoid Cell Imaging Station. A) S. subtropicum wild-type strain relief phase. B) Wild-type red fluorescence. C) S. subtropicum mutant strain, gpdA-Kat-Sur (+), relief phase. D) gpdA-Kat-Sur (+) red fluorescence. Scale bar, $100 \mu \mathrm{m}$, for all images. 


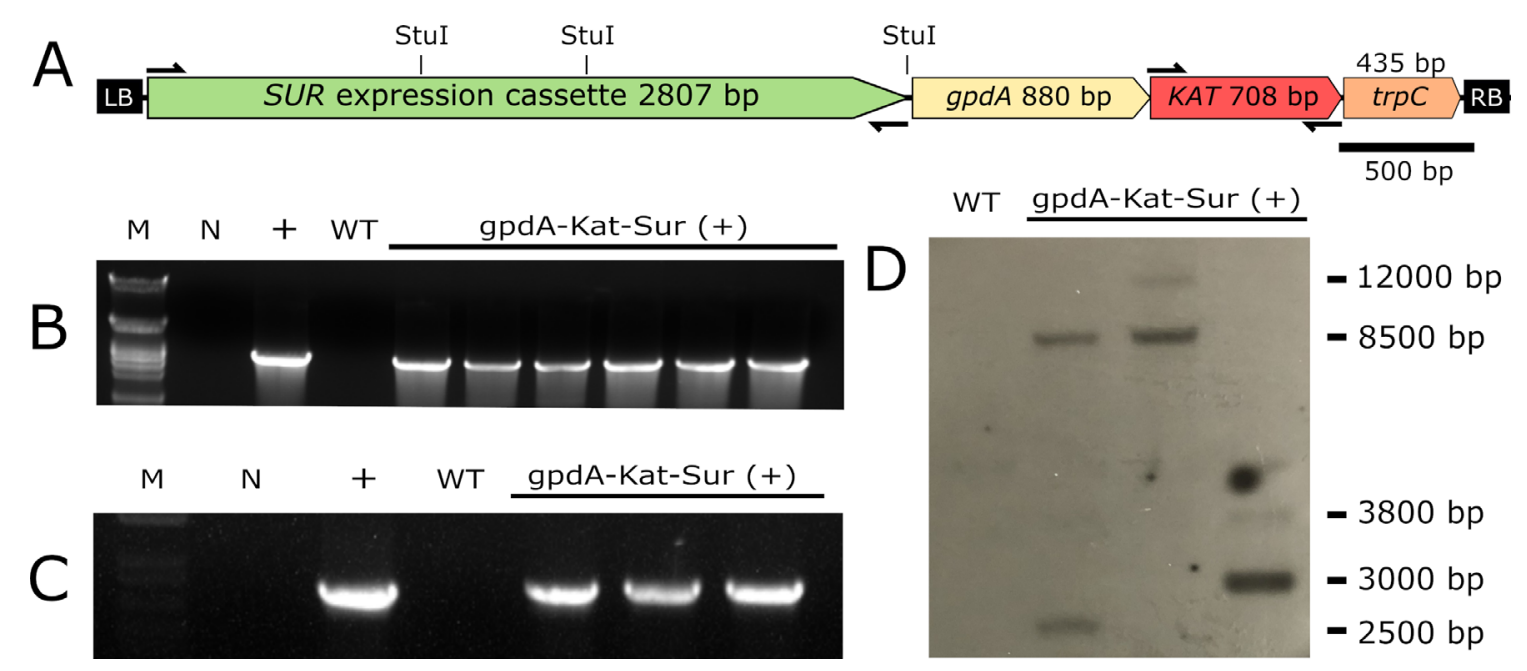

Figure 5 - Evaluation of the SUR gene and Kat expression cassette stability in the S. subtropicum mutants. Selected S. subtropicum mutants with the brightest far-red Kat-fluorescence were cultivated for five generations in MCc without CE to evaluate the mitotic stability. A) The Kat gene expression cassette (gpdA::Kat::TrpC) was cloned next to the SUR expression cassette (as displayed) in the plasmid pPZP201BK::SUR, to generate the plasmid pPZP201BK::SUR::gpdA::Kat::TrpC. B) The PCR results amplifying the $S U R$ gene ( $2800 \mathrm{bp})$. C) The PCR results amplifying the KAT CDS ( 700 bp). D) The Southern blotting results employing the KAT CDS as a probe. M - DNA Ladder; $\mathrm{N}$ - Negative control (without DNA); + pPZP201BK::SUR::gpdA::Kat::TrpC plasmid; WT - S. subtropicum wild-type strain; gpdA-Kat-Sur $(+)$ - S. subtropicum mutant strains harboring the Kat gene expression cassette and the SUR gene integrated into the genome.

Although laborious, the ATMT method has been explored in several organisms, being, usually, the first method standardized for fungi that lack established genetic transformation strategies (Idnurm et al., 2017). Although there are several ATMT protocols established, the co-cultivation of $A$. tumefaciensfungus is a central step. Small variations in A. tumefaciens strains, membranes employed/solid support, as well as mutant plating and selection, are crucial for transformation success/ failure and efficiency. The robust protocol developed for ATMT of A. awamori has been previously adapted for hard-totransform fungi (Michielse et al., 2008), as Paracoccidioides spp. (Almeida et al., 2007; Menino et al., 2012; Bailão et al., 2014; Fernandes et al., 2017; Nora et al., 2019; Silva et al., 2020), and, for that reason, this method was chosen.

As entomopathogenic species, future studies in Simplicillium spp. can focus on the heterologous expression of toxins and virulence determinants. This approach has been successfully implemented in Metarhizium spp. (Wang and St Leger, 2007; Bilgo et al., 2017). Recently, a semifield trial of a transgenic Metarhizium pingshaense expression insect-specific toxins has shown high efficiency (Lovett et al., 2019). Similarly, genetic engineering can improve the biosorption capacity of Simplicillium spp. The expression of cell wall metal-binding chimeric ligands increased $\mathrm{Cd}^{2+}$ and $\mathrm{Zn}^{2+}$ recovery in Saccharomyces cerevisiae (Vinopal et al., 2007). Furthermore, T-DNA libraries can be useful for the characterization of $S$. subtropicum genes of overall importance, enrolled in heavy metal tolerance/assimilation and virulence determinants (Zhao et al., 2014).

A diverse array of secondary metabolites has been isolated from Simplicillium species. In recent years, genome mining of secondary metabolite biosynthetic gene clusters (BGCs), coupled with knockout strains, overexpression of transcription factors, and heterologous expression of BGCs have been largely employed for the discovery of biosynthetic pathways (Gilchrist et al., 2018). Although genomes from Simplicillium spp. are not yet available, that should be one of the main goals going forward. Besides, secondary metabolites, the genome sequencing of these species, coupled with the standardized ATMT method, can reveal important aspects of the life and infection cycle of fungi from the Simplicillium genus.

\section{Acknowledgements}

This study is part of the Advanced Network of Computational Biology (RABICÓ). The manuscript has been read and approved by all named authors. The authors would like to thank to Conselho Nacional de Desenvolvimento Científico e Tecnológico (CNPq) and Coordenação de Aperfeiçoamento de Pessoal de Nível Superior (CAPES) for financial and scholarship support.

\section{Conflict of Interest}

The authors declare that there is no conflict of interest that could be perceived as prejudicial to the impartiality of the reported research.

\section{Author Contributions}

NS, MVT, RAG AMB, CLB, AS, CMAS, and CCS contributed for experimental design and results interpretation. NS contributed with species identification and phylogeny. NS, and ABP contributed with Katushka reporter plasmid construction. NS, MVT, RAB and AMB contributed with Agrobacterium tumefaciens-mediated transformation. NS, MVT, $\mathrm{ABP}$, and MSC contributed with screening of the transformants by fluorescent imaging. NS and MSC contributed with Southern blotting analysis. AS, CMAS, and CCS contributed with reagents/materials/analysis tools. NS, MVT, AMB, CLB, AS, CMAS, and CCS contributed with manuscript redaction. All the authors contributed to the article and approved the submitted version. 


\section{References}

Almeida AJ, Carmona JA, Cunha C, Carvalho A, Rappleye CA, Goldman WE, Hooykaas PJ, Leão C, Ludovico P and Rodrigues F (2007) Towards a molecular genetic system for the pathogenic fungus Paracoccidioides brasiliensis. Fungal Genet Biol 44:1387-1398.

Bailão EFLC, Parente JA, Pigosso LL, de Castro KP, Fonseca FL, Silva-Bailão MG, Báo SN, Bailão AM, Rodrigues ML, Hernandez O et al. (2014) Hemoglobin uptake by Paracoccidioides spp. is receptor-mediated. PLoS Negl Trop Dis 8:e2856.

Berendsen RL, Baars JJP, Kalkhove SIC, Lugones LG, Wosten HAB and Bakker PAHM (2010) Lecanicillium fungicola: causal agent of dry bubble disease in white-button mushroom. Mol Plant Pathol 11:585-595.

Bilgo E, Lovett B, Fang W, Bende N, King GF, Diabate A and St. Leger RJ (2017) Improved efficacy of an arthropod toxin expressing fungus against insecticide-resistant malaria-vector mosquitoes. Sci Rep 7:3433.

Bundock P, den Dulk-Ras A, Beijersbergen A and Hooykaas PJ (1995) Trans-kingdom T-DNA transfer from Agrobacterium tumefaciens to Saccharomyces cerevisiae. EMBO J 14:32063214.

Chen R-S, Huang C-C, Li J-C and Tsay J-G (2008) First report of Simplicillium lanosoniveum causing brown spot on Salvinia auriculata and S. molesta in Taiwan. Plant Dis 92:1589.

Crous PW, Luangsa-Ard JJ, Wingfield MJ, Carnegie AJ, HernándezRestrepo M, Lombard L, Roux J, Barreto RW, Baseia IG, Cano-Lira JF et al. (2018) Fungal Planet description sheets: 785-867. Persoonia 41:238-417.

Dai Y, Lin Y, Pang X, Luo X, Salendra L, Wang J, Zhou X, Lu Y, Yang B and Liu Y (2018) Peptides from the Soft Coral-associated fungus Simplicillium sp. SCSIO41209. Phytochemistry 154: $56-62$.

de Groot MJ, Bundock P, Hooykaas PJ and Beijersbergen AG (1998) Agrobacterium tumefaciens-mediated transformation of filamentous fungi. Nat Biotechnol 16:839-842.

Faria MR de and Wraight SP (2007) Mycoinsecticides and Mycoacaricides: A comprehensive list with worldwide coverage and international classification of formulation types. Biol Control 43:237-256.

Fernandes FF, Oliveira AF, Landgraf TN, Cunha C, Carvalho A, Vendruscolo PE, Gonçales RA, Almeida F, da Silva TA, Rodrigues F et al. (2017) Impact of Paracoccin gene silencing on Paracoccidioides brasiliensis virulence. MBio 8:e00537-17.

Fu C, Donovan WP, Shikapwashya-Hasser O, Ye X and Cole RH (2015) Hot fusion: An efficient method to clone multiple DNA fragments as well as inverted repeats without ligase. PLoS One 9:e115318.

Gilchrist CLM, Li H and Chooi Y-H (2018) Panning for gold in mould: can we increase the odds for fungal genome mining? Org Biomol Chem 16:1620-1626.

Green M and Sambrook J (2012) Molecular Cloning: A Laboratory Manual, 4th Edition. Cold Spring Harbour, Spring Harbor Laboratory Press, New York, $2.028 \mathrm{p}$.

Guindon S, Dufayard JF, Lefort V, Anisimova M, Hordijk W and Gascuel O (2010) New algorithms and methods to estimate maximum-likelihood phylogenies: Assessing the performance of PhyML 3.0. Syst Biol 59:307-321.

Haleva L, Lopes W, Barcellos VA, Schrank A and Vainstein MH (2020) The contest of microbial pigeon neighbors: Interspecies competition between Serratia marcescens and the human pathogen Cryptococcus neoformans. Fungal Biol 124:629-638.
Harm GFS, Papanicolaou A, Cuddy WS, Park RF and Moffitt MC (2018) Draft genome sequence of the fungus Lecanicillium psalliotae strain HWLR35, isolated from a wheat leaf infected with leaf rust (Caused by Puccinia triticina). Genome Announc 6:e 01442-17

Idnurm A, Bailey AM, Cairns TC, Elliott CE, Foster GD, Ianiri $\mathrm{G}$ and Jeon J (2017) A silver bullet in a golden age of functional genomics: the impact of Agrobacterium-mediated transformation of fungi. Fungal Biol Biotechnol 4:6.

Idnurm A and Meyer V (2014) Welcome to fungal biology and biotechnology. Fungal Biol Biotechnol 1:8.

Jin Z, Deng S, Wen Y, Jin Y, Pan L, Zhang Y, Black T, Jones KC, Zhang H and Zhang D (2019) Application of Simplicillium chinense for $\mathrm{Cd}$ and $\mathrm{Pb}$ biosorption and enhancing heavy metal phytoremediation of soils. Sci Total Environ 697:134148.

Jin Z, Xie L, Zhang T, Liu L, Black T, Jones KC, Zhang H, Wang $\mathrm{X}$, Jin $\mathrm{N}$ and Zhang D (2020) Interrogating cadmium and lead biosorption mechanisms by Simplicillium chinense via infrared spectroscopy. Environ Pollut 263:114419.

Kepler RM, Luangsa-Ard JJ, Hywel-Jones NL, Quandt CA, Sung G-H, Rehner SA, Aime MC, Henkel TW, Sanjuan T, Zare $\mathrm{R}$ et al. (2017) A phylogenetically-based nomenclature for Cordycipitaceae (Hypocreales). IMA Fungus 8:335-353.

Khan S, Ullah MW, Siddique R, Nabi G, Manan S, Yousaf M and Hou $\mathrm{H}$ (2016) Role of recombinant DNA technology to improve life. Int J Genomics 2016:2405954.

Li D, Tang Y, Lin J and Cai W (2017) Methods for genetic transformation of filamentous fungi. Microb Cell Fact 16:168.

Lin L, Wang F and Wei D (2011) Chlorimuron ethyl as a new selectable marker for disrupting genes in the insect-pathogenic fungus Metarhizium robertsii. J Microbiol Methods 87:241-243.

Lovett B, Bilgo E, Millogo SA, Ouattarra AK, Sare I, Gnambani EJ, Dabire RK, Diabate A and St. Leger RJ (2019) Transgenic Metarhizium rapidly kills mosquitoes in a malaria-endemic region of Burkina Faso. Science 364:894-897.

Loytynoja A and Goldman N (2010) webPRANK: a phylogeny-aware multiple sequence aligner with interactive alignment browser. BMC Bioinformatics 11:6.

Menino JF, Almeida AJ and Rodrigues F (2012) Gene knockdown in Paracoccidioides brasiliensis using antisense RNA. Methods Mol Biol 845:187-198.

Michielse CB, Hooykaas PJJ, van den Hondel CAMJJ and Ram AFJ (2008) Agrobacterium-mediated transformation of the filamentous fungus Aspergillus awamori. Nat Protoc 3:16711678

Nonaka K, Kaifuchi S, Ōmura S and Masuma R (2013) Five new Simplicillium species (Cordycipitaceae) from soils in Tokyo, Japan. Mycoscience 54:42-53.

Nora LC, Gonçales RA, Martins-Santana L, Ferreira BH, Rodrigues F and Silva-Rocha R (2019) Synthetic and minimalist vectors for Agrobacterium tumefaciens-mediated transformation of fungi . Genet Mol Biol 42:395-398.

Ong GH, Ho XH, Shamkeeva S, Manasha Savithri Fernando AS and Wong LS (2017) Biosorption study of potential fungi for copper remediation from Peninsular Malaysia. Remediat J 27:59-63.

Padilla-Guerrero IE and Bidochka MJ (2017) AgrobacteriumMediated Co-transformation of multiple genes in Metarhizium robertsii. Mycobiology 45:84-89.

Ruiz-Díez B (2002) Strategies for the transformation of filamentous fungi. J Appl Microbiol 92:189-195.

Rukachaisirikul V, Chinpha S, Saetang P, Phongpaichit S, Jungsuttiwong S, Hadsadee S, Sakayaroj J, Preedanon S, Temkitthawon P and Ingkaninan K (2019) Depsidones and a dihydroxanthenone from the endophytic fungi Simplicillium lanosoniveum (J.F.H. Beyma) Zare \& W. Gams PSU-H168 and PSU-H261. Fitoterapia 138:104286. 
Sbaraini N, Bellini R, Penteriche AB, Guedes RLM, Garcia AWA, Gerber AL, Vainstein MH, de Vasconcelos ATR, Schrank A and Staats CC (2019) Genome-wide DNA methylation analysis of Metarhizium anisopliae during tick mimicked infection condition. BMC Genomics 20:836.

Sela I, Ashkenazy H, Katoh K and Pupko T (2015) GUIDANCE2: accurate detection of unreliable alignment regions accounting for the uncertainty of multiple parameters. Nucleic Acids Res 43:w7-w14

Shcherbo D, Merzlyak EM, Chepurnykh T V, Fradkov AF, Ermakova G V, Solovieva EA, Lukyanov KA, Bogdanova EA, Zaraisky AG, Lukyanov S et al. (2007) Bright far-red fluorescent protein for whole-body imaging. Nat Methods 4:741-746.

Shin TS, Yu NH, Lee J, Choi GJ, Kim J-C and Shin CS (2017) Development of a biofungicide using a mycoparasitic fungus Simplicillium lamellicola $\mathrm{BCP}$ and its control efficacy against gray mold diseases of tomato and ginseng. Plant Pathol J 33: 337-344.

Silva MG, de Curcio JS, Silva-Bailão MG, Lima RM, Tomazett MV, de Souza AF, Cruz-Leite VRM, Sbaraini N, Bailão AM, Rodrigues F et al. (2020) Molecular characterization of siderophore biosynthesis in Paracoccidioides brasiliensis. IMA Fungus 11:11.

Staats CC, Junges A, Fitarelli M, Furlaneto MC, Vainstein MH and Schrank A (2007) Gene inactivation mediated by Agrobacterium tumefaciens in the filamentous fungi Metarhizium anisopliae. Appl Microbiol Biotechnol 76:945-950.

Sweigard JA, Chumley F, Carroll A, Farrall L and Valent B (1997) A series of vectors for fungal transformation. Fungal Genet Rep 44:52-53.

Takata K, Iwatsuki M, Yamamoto T, Shirahata T, Nonaka K, Masuma R, Hayakawa Y, Hanaki H, Kobayashi Y, Petersson GA et al. (2013) Aogacillins A and B produced by Simplicillium sp. FKI-5985: new circumventors of arbekacin resistance in MRSA. Org Lett 15:4678-4681.

Tuli HS, Sandhu SS and Sharma AK (2014) Pharmacological and therapeutic potential of Cordyceps with special reference to Cordycepin. 3 Biotech 4:1-12.

Uchida R, Kondo A, Yagi A, Nonaka K, Masuma R, Kobayashi K and Tomoda H (2019) Simpotentin, a new potentiator of amphotericin $B$ activity against $C$ andida albicans, produced by Simplicillium minatense FKI-4981. J Antibiot (Tokyo) 72:134-140.
Vinopal S, Ruml T and Kotrba P (2007) Biosorption of Cd2+ and $\mathrm{Zn} 2+$ by cell surface-engineered Saccharomyces cerevisiae. Int Biodeterior Biodegradation 60:96-102.

Walton FJ, Idnurm A and Heitman J (2005) Novel gene functions required for melanization of the human pathogen Cryptococcus neoformans. Mol Microbiol 57:1381-1396.

Wang CS and St Leger RJ (2007) A scorpion neurotoxin increases the potency of a fungal insecticide. Nat Biotechnol 25:1455-1456.

Ward NA, Robertson CL, Chanda AK and Schneider RW (2012) Effects of Simplicillium lanosoniveum on Phakopsora pachyrhizi, the soybean rust pathogen, and its use as a biological control agent. Phytopathology 102:749-760.

Youssef FS, Ashour ML, Singab ANB and Wink M (2019) A comprehensive review of bioactive peptides from marine fungi and their biological significance. Mar Drugs 17(10):559.

Zhao H, Xu C, Lu H-L, Chen X, St. Leger RJ and Fang W (2014) Host-to-Pathogen gene transfer facilitated infection of insects by a pathogenic fungus. PLoS Pathog 10:e1004009.

Zimmermann G (2007) Review on safety of the entomopathogenic fungi Beauveria bassiana and Beauveria brongniartii. Biocontrol Sci Technol 17:553-596.

\section{Supplementary material}

Supplementary Data S1 - Alignment of ITS sequences used to generate de Simplicillium species tree.

Table S1 - Sequences of primers used in this work.

Figure S1 - pPZP201BK::SUR::gpdA::Kat::TrpC plasmid map.

Supplementary Data S2 - pPZP201BK::SUR::gpdA::Kat::TrpC plasmid sequence.

Figure S2 - Confirmation of fluorescence detection in the fungal transformants.

Associate Editor: Marcio de Castro Silva Filho

License information: This is an open-access article distributed under the terms of the Creative Commons Attribution License (type CC-BY), which permits unrestricted use, distribution and reproduction in any medium, provided the original article is properly cited. 